approvals in the US, according to Bernstein's Gal. Amgen filed in 2005 an application with the FDA for a copy of North Chicago-based AbbVie's Humira (adalimumab), a best-selling treatment for rheumatoid arthritis that garnered $\$ 14$ billion in sales last year. Sandoz-a unit of Basel, Switzerland-based Novartis-last October asked the FDA to back a knockoff of Amgen's own Enbrel (etanercept), a drug to treat autoimmune diseases such as rheumatoid arthritis that had $\$ 5.3$ billion in sales in 2015 .

The agency's endorsement and subsequent regulatory approval came despite the protests of Johnson \& Johnson, the parent company to Janssen Biotech, over the use of extrapolation. "We see lots of reasons for questioning whether these drugs will work the same," says Jay Siegel, J\&J's chief biotechnology officer. "We hoped and expected that the FDA take those considerations seriously." J\&J has about $\$ 4.5$ billion in annual US Remicade sales at stake.

Europe's drug regulator also based its 2013 decision to approve the Celltrion product, called Remsima in Europe, on extrapolation. A biosimilar version of Remicade has already been approved in various regions, including parts of Europe, Canada, South Korea, Japan, and India.

In 2014, the Canadian drug regulator Health Canada approved Celltrion's infliximab copy for all indications except ulcerative colitis and Crohn's disease (collectively referred to as inflammatory bowel disease, or IBD), with the conclusion that extrapolation of data from the settings of rheumatoid arthritis and ankylosing spondylitis to IBD indications could not be recommended owing to lingering uncertainty regarding the role and impact of small differences in antibody-dependent cellular cytotoxicity (ADCC) that might have relevance in these indications.

In its decision, Health Canada argued that this position is supported by the observation that certolizumab pegol, marketed by Brusselsbased UCB as Cimzia, which lacks the ability to induce ADCC, displays only marginal efficacy in patients with Crohn's disease.

The FDA's decision also may have an impact on the US commercial success of Inflectra, according to Bernstein's Gal. Because the approval includes only a subset of indications, it may have dissuaded doctors worried about quality from prescribing the drug. "The most obvious argument against biosimilars would be that even regulators are conflicted about approving biosimilars," says Gal.

In some European countries, the copy has essentially displaced the branded drug, with the market share of Celltrion's product at over 90\% in Norway, according to Celltrion's Kudrin. In February, the British Society of Gastroenterology released new guidance advising that patients whose condition is considered by medical professionals to be stable can be switched to biosimilar infliximab. Merck, of Kenilworth, New Jersey, which markets
Remicade in Europe, saw sales of the drug drop to $\$ 1.79$ billion last year from $\$ 2.3$ billion in the previous year.

In a separate draft guidance, the FDA set new rules on labeling biosimilars. The new document comes just over a year after the US regulator approved the first biosimilar Zarxio. But the labeling used for the drug was heavily criticized by pharma and, as a result, the FDA recommends that, to avoid confusion, biosimilars' labels typically should not include clinical trial data demonstrating biosimilarity to their reference products. The draft guidance also makes recommendations of when to use the biosimilar product name (such as 'Inflectra' of infliximab-dyyb), just the reference product name ('Remicade'), or the core product name ('infliximab'). The issue of interchangeabilityswitching between the reference product and a biosimilar-remains to be addressed.

It isn't clear when Inflectra will hit the US market. New York-based Pfizer, which will market the biosimilar, has stated that it is preparing the drug's launch for later this year. J\&J is hoping to keep Inflectra on the sidelines for a bit longer. The company sued Celltrion in federal court in Massachusetts last year, alleging that Inflectra would infringe six patents for Remicade, including one that expires in 2027. The patent covering the drug's composition is due to expire in 2018. Celltrion has denied the infringement allegations.

Eva von Schaper Munich, Germany

\title{
Bento Lab
}

A DNA laboratory small enough to fit into a laptop-sized bag could become a 'must have' accessory for citizen scientists. The Bento Lab is an easy-to-use DNA analysis kit created by Bethan Wolfenden and Philipp Boeing at University College London. They identified the need for simple equipment for running experiments after organizing hands-on biotech workshops for people curious about genetics. The Bento Lab comes with PCR thermocycler, a centrifuge, and a gel electrophoresis box with an LED transilluminator. Because it has potential for interfacing with a computer or a minION DNA sequencer from Oxford Nanopore, the Bento Lab could appeal to professional scientists too. The team has just raised funds through Kickstarter to fund the first production run. Price point is about $£ 700$ (\$993).

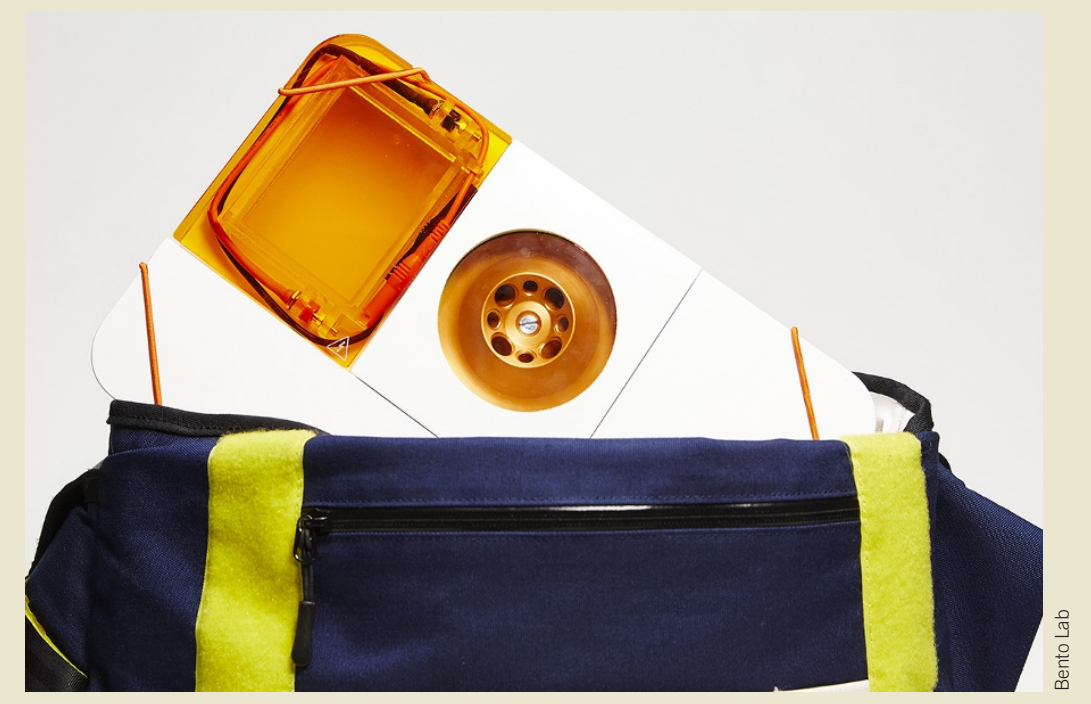

